\title{
Abbreviations
}

$\begin{array}{ll}\text { AIOC } & \text { Anglo-Iranian Oil Company } \\ \text { ANC } & \text { African National Congress } \\ \text { ANZUS } & \text { Australia, New Zealand, United States Security Treaty } \\ \text { APOC } & \text { Anglo-Persian Oil Company } \\ \text { ARAMCO } & \text { Arabian American Oil Company } \\ \text { ASEAN } & \text { Association of Southeast Asian Nations } \\ \text { BDEE } & \text { British Documents on the End of Empire } \\ \text { CENTO } & \text { Central Treaty Organization } \\ \text { CHUR } & \text { Churchill Archives, Cambridge, United Kingdom } \\ \text { CIA } & \text { Central Intelligence Agency } \\ \text { CIAA } & \text { US Central Intelligence Agency Archives } \\ \text { CINC } & \text { Composite Index of National Capabilities } \\ \text { DIRCO } & \text { South Africa Department of International Relations and } \\ & \text { Co-operation Archives, Pretoria, South Africa } \\ \text { DNSA } & \text { Digital National Security Archive } \\ \text { FAPLA } & \text { People's Armed Forces for the Liberation of Angola } \\ \text { FRUS } & \text { Foreign Relations of the United States } \\ \text { GDP } & \text { gross domestic product } \\ \text { GNP } & \text { gross national product } \\ \text { HEU } & \text { highly enriched uranium } \\ \text { ICBM } & \text { intercontinental ballistic missile } \\ \text { IMF } & \text { International Monetary Fund } \\ \text { IRBM } & \text { intermediate range ballistic missile } \\ \text { JCS } & \text { Joint Chiefs of Staff } \\ \text { MID } & \text { militarized interstate dispute } \\ \text { MK } & \text { Umkhonte we Sizwe }\end{array}$




$\begin{array}{ll}\text { MOD } & \text { United Kingdom Ministry of Defence } \\ \text { MPLA } & \text { Popular Movement for the Liberation of Angola } \\ \text { NATO } & \text { North Atlantic Treaty Organization } \\ \text { NATOSD } & \text { NATO Strategy Documents } \\ \text { NIC } & \text { National Identity Conception } \\ \text { NPT } & \text { Treaty on the Nonproliferation of Nuclear Weapons } \\ \text { NSA } & \text { National Security Archive } \\ \text { NSC } & \text { National Security Council } \\ \text { OAU } & \text { Organisation of African Unity } \\ \text { OPC } & \text { Office of Policy Coordination } \\ \text { PLAN } & \text { People's Liberation Army of Namibia } \\ \text { PPPUS } & \text { Public Papers of the Presidents of the United States } \\ \text { PRC } & \text { People's Republic of China } \\ \text { RAF } & \text { Royal Air Force } \\ \text { REAG } & \text { Reagan Presidential Library, Simi Valley, California } \\ \text { SADF } & \text { South African Defence Force } \\ \text { SEATO } & \text { South East Asia Treaty Organization } \\ \text { SWAPO } & \text { South West African People's Organization } \\ \text { TRUM } & \text { Truman Presidential Library, Independence, Missouri } \\ \text { UKHoP } & \text { Records of the United Kingdom Houses of Parliament } \\ & \text { (Hansard) } \\ \text { UKNA } & \text { United Kingdom National Archives, Kew, United Kingdom } \\ \text { UN } & \text { United Nations } \\ \text { UNITA } & \text { National Union for the Total Independence of Angola } \\ \text { USSR } & \text { Union of Soviet Socialist Republics } \\ \text { WWCDA } & \text { Woodrow Wilson Center Digital Archive }\end{array}$




\section{Nuclear Reactions}


